\title{
Pyruvate Kinase M2: A Novel Biomarker for the Early Detection of Acute Kidney Injury
}

\author{
Ji Hyun Cheon', Sun Young Kim², Ji Yeon Son', Ye Rim Kang', Ji Hye An', Ji Hoon Kwon', \\ Ho Sub Song ${ }^{1}$, Aree Moon ${ }^{2}$, Byung Mu Lee ${ }^{1}$ and Hyung Sik Kim ${ }^{1}$ \\ ${ }^{1}$ School of Pharmacy, Sungkyunkwan University, Suwon, Korea \\ ${ }^{2}$ College of Pharmacy, Duksung Women's University, Seoul, Korea
}

(Received December 14, 2015; Revised December 22, 2015; Accepted December 23, 2015)

\begin{abstract}
The identification of biomarkers for the early detection of acute kidney injury (AKI) is clinically important. Acute kidney injury (AKI) in critically ill patients is closely associated with increased morbidity and mortality. Conventional biomarkers, such as serum creatinine ( $\mathrm{SCr}$ ) and blood urea nitrogen (BUN), are frequently used to diagnose AKI. However, these biomarkers increase only after significant structural damage has occurred. Recent efforts have focused on identification and validation of new noninvasive biomarkers for the early detection of AKI, prior to extensive structural damage. Furthermore, AKI biomarkers can provide valuable insight into the molecular mechanisms of this complex and heterogeneous disease. Our previous study suggested that pyruvate kinase M2 (PKM2), which is excreted in the urine, is a sensitive biomarker for nephrotoxicity. To appropriately and optimally utilize PKM2 as a biomarker for AKI requires its complete characterization. This review highlights the major studies that have addressed the diagnostic and prognostic predictive power of biomarkers for AKI and assesses the potential usage of PKM2 as an early biomarker for AKI. We summarize the current state of knowledge regarding the role of biomarkers and the molecular and cellular mechanisms of AKI. This review will elucidate the biological basis of specific biomarkers that will contribute to improving the early detection and diagnosis of AKI.
\end{abstract}

Key words: Acute kidney injury, Pyruvate kinase M2, Biomarker

\section{INTRODUCTION}

Acute kidney injury (AKI) is defined as a sudden decline in the glomerular filtration rate (GFR) and leads to high patient mortality. During AKI, many changes occur at the cellular and molecular level in the kidney $(1,2)$. Over the past decade, there have been promising advances in the clinical diagnosis of AKI, but the exact mechanisms of this disease are not entirely understood because a wide array of molecules are involved in its induction (3-5). Earlier detection may reduce the risk of AKI. Although sensitive and

Correspondence to: Hyung Sik Kim, School of Pharmacy, Sungkyunkwan University, Suwon 440-746, Korea

E-mail: hkims@skku.edu

Abbreviations: $\mathrm{HK}$, hexokinase; G6PD, glucose-6-phosphate dehydrogenase; LDHA, lactate dehydrogenase A; PKM2, pyruvate kinase M2.

This is an Open-Access article distributed under the terms of the Creative Commons Attribution Non-Commercial License (http:// creativecommons.org/licenses/by-nc/3.0) which permits unrestricted non-commercial use, distribution, and reproduction in any medium, provided the original work is properly cited. reliable noninvasive biomarkers have been discovered, serum creatinine ( $\mathrm{SCr}$ ) and blood urea nitrogen (BUN) are still routinely used in clinical trials for the detection of AKI. However, they are not useful in early detection of AKI because changes in SCr and BUN levels occur only after severe histopathological damage in the kidney $(6,7)$. Furthermore, it is worth noting that changes in SCr and BUN are not specific to AKI and are influenced by a variety of non-renal factors, such as age, muscle mass, and diet, which hinder their use in AKI diagnosis $(8,9)$. Recently, the rate of discovery of new biomarkers has increased substantially, and new potential biomarkers have been introduced. However, which biomarkers are the most useful for the detection of AKI is still unknown because measuring biomarkers at an optimal time is necessary to understand disease progression. Furthermore, biomarkers should not be measured indirectly, and their measurements must be directly related to tissue damage in clinical trials.

This review will focus on the current status of the most promising biomarkers for detecting AKI, and we will also describe the characteristics of several biomarkers currently in use. AKI causes urinary excretion of several enzymes 
which are often indicative of injury in specific anatomical locations; these biomarkers are either upregulated or leak from disrupted cell membranes. These enzymes include gamma-glutamyl transpeptidase (GGT), alkaline phosphatase (ALP), beta-galactosidase, alpha-glutathione-S-transferase $(\alpha \mathrm{GST})$, and N-acetyl-beta-D-glucosaminidase (NAG), which are found predominantly in the proximal tubules. The current understanding of the novel biomarker glycolytic enzyme pyruvate kinase M2 (PKM2) is also presented.

\section{CURRENTLY PROPOSED BIOMARKERS FOR EARLY DETECTION OF AKI}

The clinical definition of AKI is a rapid loss of kidney function within 7 days (10). AKI has multiple causes, including renal ischemia, exposure to nephrotoxicants, inflammatory processes, and obstruction of the urinary tract (11). Patients with AKI may have an increased risk of chronic kidney disease (CKD). The causes of AKI are commonly categorized as prerenal, intrinsic, and postrenal $(11,12)$ and its probable biomarkers are shown in Fig. 1. These biomarkers can help identify the stage of AKI and the extent of renal cell damage. The characteristics of early biomarkers of AKI are listed in Table 1. Several molecules secreted in the urine, such as creatinine, kidney injury molecule-1 (KIM-1), clusterin, neutrophil gelatinase-associated lipocalin (NGAL), tissue inhibitors of metalloproteinases-1 (TIMP-1), and cystatin $\mathrm{C}$, have been suggested as biomarkers for the detection of AKI (13). Increased use of these biomarkers will be beneficial in facilitating early diagnosis, guiding targeted intervention, and monitoring disease progression and resolution (14).

\section{Neutrophil gelatinase-associated lipocalin (NGAL).}

NGAL, a lipocalin protein, is associated with innate immunity as it binds iron and thus limit bacterial growth (25). It is synthesized during the maturation process of granulocytes, which are involved in innate immunity (26). NGAL is highly upregulated following renal injury, and it can be detected in the serum and urine within $2 \mathrm{hr}$ of injury, prior to functional changes in the kidney (27). In AKI, NGAL is expressed in proximal tubule cells and then readily secreted into the urine without reabsorption; this occurs before $\mathrm{SCr}$ levels rise (28). Therefore, NGAL is a useful biomarker for the early diagnosis of AKI. In clinical studies, normal serum NGAL levels were approximately $80 \mathrm{ng} / \mathrm{mL}$ in healthy individuals $(29,30)$, but increase $>10$-fold in serum and $>100$ fold in urine following AKI (27). The role of NGAL as an AKI biomarker has been established. In our previous study, mild histopathological alterations were noted on day 1 , and these changes became severe on day 3 and 5 in cisplatintreated rats. Furthermore, the levels of new urinary proteinbased biomarkers, KIM-1 and NGAL, and osteopontin, were significantly elevated on day 3 and 5 (31).

Xin et al. (2008) reported a significant increase in serum NGAL levels within $2 \sim 4 \mathrm{hr}$ in patients undergoing cardiac surgery (32). Moreover, a substantial increase in NGAL levels was negatively correlated with renal function in unilateral renal ischemia models (33). However, there are some limitations to the value of NGAL as a biomarker for AKI.

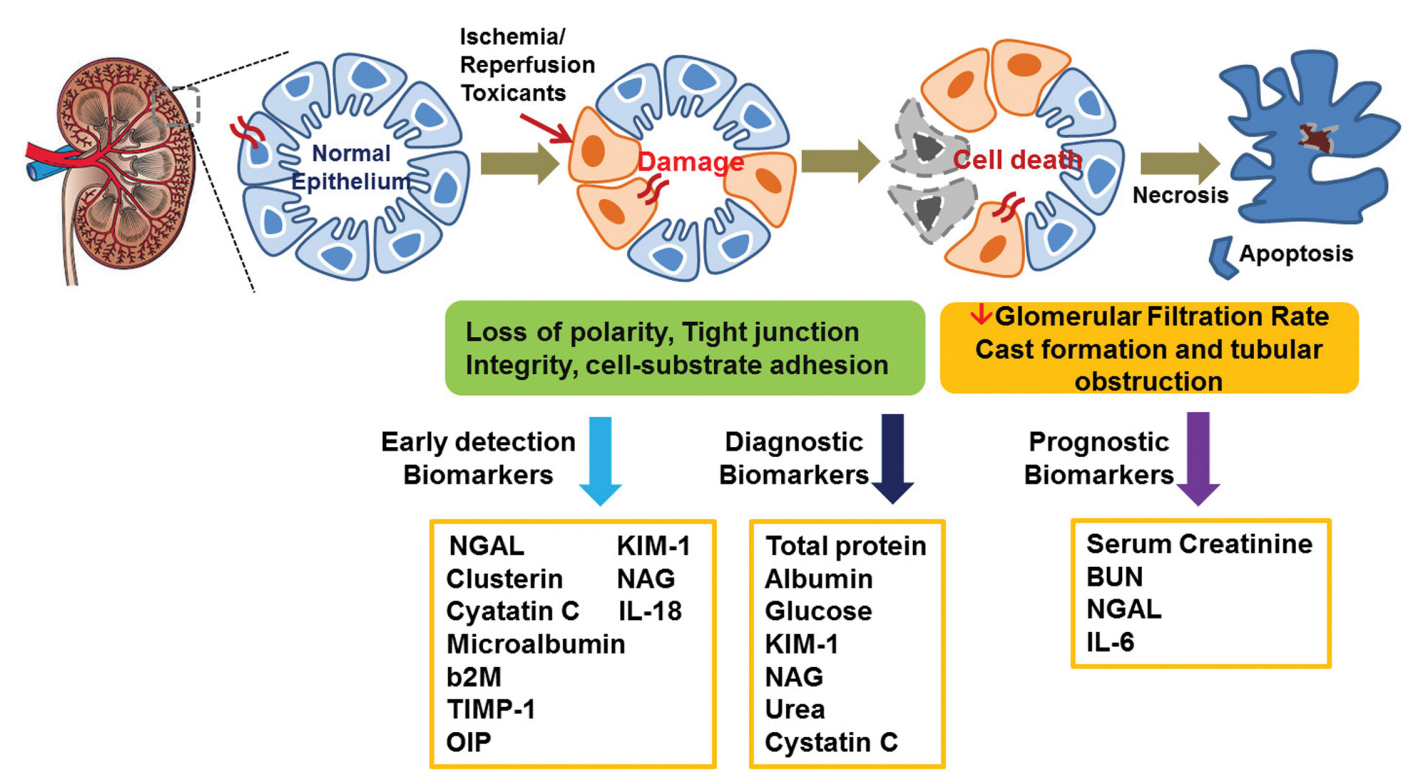

Fig. 1. The cellular mechanisms involved in acute kidney injury and its urinary biomarkers. Biomarkers are renal or non-renal derived molecules that report the functional status of kidney filtration and tubule injury. Markers may be non-renal molecules that are filtered, secreted or reabsorbed, molecules that are constitutively expressed, or molecules that are up-regulated by inflammation-mediated immune cells. 
Table 1. Characteristics of biomarkers for the early detection of acute kidney injury

\begin{tabular}{|c|c|c|c|c|}
\hline Biomarker & Physiological roles & Molecular weight & Source & References \\
\hline Creatinine & $\begin{array}{l}\text { Metabolic product of skeletal muscle creatine and creatine } \\
\text { phosphate }\end{array}$ & $113 \mathrm{Da}$ & Serum & $6-8$ \\
\hline Albumin & $\begin{array}{l}\text { Protein which binds the compounds and is used to detect albu- } \\
\text { minuria, the secretion of albumin into the urine }\end{array}$ & $66.5 \mathrm{kDa}$ & Urine & 15 \\
\hline Kidney injury molecule-1 & $\begin{array}{l}\text { Transmembrane glycoprotein with immunoglobulin and mucin } \\
\text { domains }\end{array}$ & $90 \mathrm{kDa}$ & $\begin{array}{l}\text { Serum } \\
\text { Urine }\end{array}$ & 15 \\
\hline $\begin{array}{l}\text { Neutrophil gelatinease- } \\
\text { associated lipocalin }\end{array}$ & Epithelial cell origin & $21 \mathrm{kDa}$ & $\begin{array}{l}\text { Serum } \\
\text { Urine }\end{array}$ & $27-30$ \\
\hline$\beta 2$-microglobulin & $\begin{array}{l}\text { Low molecular weight protein with sequence homology to } \\
\text { immunoglobulins }\end{array}$ & $11.8 \mathrm{kDa}$ & $\begin{array}{l}\text { Serum } \\
\text { Urine }\end{array}$ & 16 \\
\hline Clusterin & $\begin{array}{l}\text { Regulation of the cytolytic activity of the membrane attack } \\
\text { complex of complement }\end{array}$ & $70 \mathrm{kDa}$ & $\begin{array}{l}\text { Serum } \\
\text { Urine }\end{array}$ & $17-19$ \\
\hline Cystatin C & $\begin{array}{l}\text { Lysosomal protease inhibitor expressed by all nucleated cells. } \\
\text { A good indicator of glomeral filtrate Rate (GFR) function }\end{array}$ & $13 \mathrm{kDa}$ & $\begin{array}{l}\text { Serum } \\
\text { Urine }\end{array}$ & $47-49$ \\
\hline $\begin{array}{l}\text { Metallopeptidase } \\
\text { inhibitor } 1\end{array}$ & $\begin{array}{l}\text { TIMP-1 activity indicates biochemical perturbations due to } \\
\text { renal toxicity. }\end{array}$ & $23.17 \mathrm{kDa}$ & $\begin{array}{l}\text { Serum } \\
\text { Urine }\end{array}$ & 20 \\
\hline Interleukin-18 & $\begin{array}{l}\text { A proinflammatory cytokine released in response to injury to } \\
\text { renal tubular epithelial cells }\end{array}$ & $24 \mathrm{kDa}$ & $\begin{array}{l}\text { Serum } \\
\text { Urine }\end{array}$ & 21 \\
\hline Osteopontin & $\begin{array}{l}\text { Osteopontin levels increase in rat models and humans follow- } \\
\text { ing nephrotoxicity }\end{array}$ & $44 \mathrm{kDa}$ & $\begin{array}{l}\text { Serum } \\
\text { Urine }\end{array}$ & 23 \\
\hline $\begin{array}{l}\alpha \text {-Glutathione-S- } \\
\text { Transferase }\end{array}$ & $\begin{array}{l}\text { Phase II detoxification enzyme that catalyzes the conjugation of } \\
\text { the reduced form of glutathione (GSH). Proximal tubular injury }\end{array}$ & $25 \mathrm{kDa}$ & Urine & 22 \\
\hline Intestinal trefoil factor & Decreased TFF3 level correlate with nephrotoxicity & $6.7 \mathrm{kDa}$ & $\begin{array}{l}\text { Serum } \\
\text { Urine }\end{array}$ & 24 \\
\hline
\end{tabular}

NGAL appears to be less sensitive and specific in studies on the multifactorial causes of AKI. Sprenkle et al. (2013) did saw no increase in urinary NGAL levels in partial nephrectomy patients $24 \mathrm{hr}$ after surgery (34). Similarly, a significant change in urinary NGAL levels was not observed in 40 nephrolithiasis patients treated with shock-wave lithotripsy (35). Cisplatin markedly increases tubule cell necrosis and apoptosis in experimental animals. Our previous study indicated that NGAL protein expression in the kidney rapidly increased within $3 \mathrm{hr}$ after cisplatin treatment. Similarly, urinary excretion of NGAL was highly increased within $3 \mathrm{hr}$ after cisplatin administration. However, urinary NAG and SCr levels were not significantly increased until $96 \mathrm{hr}$ after cisplatin treatment (31). Our results indicate that NGAL is an early and quantitative urinary biomarker for cisplatin nephrotoxicity.

Kidney injury molecule-1 (KIM-1). KIM-1 is a type-1 transmembrane glycoprotein with unknown function. KIM1 is not expressed in normal kidney tissue but is expressed in proximal tubular cells after ischemic or nephrotoxic injury $(36,37)$. Previous reports have shown that KIM-1 is an outstanding biomarker of kidney injury and is better able to predict proximal tubule injury in a rat model than is $\mathrm{SCr}$
(38). Urinary KIM-1 levels can be detected within $24 \mathrm{hr}$ of acute tubular necrosis, even when SCr concentrations do not increase. van Timmeren et al. indicated that KIM-1 was primarily expressed on the luminal side of dedifferentiated proximal tubules, in areas with fibrosis and inflammation (38). KIM-1 can be detected in the urine immediately following injury. A strong correlation between immunohistochemical KIM-1 expression and tubular cell injury was shown in renal allograft biopsies of patients with active antibody-mediated transplant rejection (39). In addition, children with AKI following cardiac surgery have elevated urinary KIM-1 levels $12 \mathrm{hr}$ after surgery (40).

KIM-1 levels in the urine are strongly related to tubular KIM-1 expression in experimental models and in humans with renal disease (41). To fully understand the diagnostic and predictive value of urinary KIM-1 as an AKI biomarker, we characterized cisplatin-induced AKI animal models, which will be helpful for early clinical detection and diagnosis of AKI $(31,42)$. We also identified KIM-1 as a potential in vitro biomarker for nephrotoxicity (42). To obtain in vivo validation of the in vitro data, we measured KIM-1 levels in the urine of rats treated with cisplatin. The levels of KIM-1 were normalized to urinary $\mathrm{Cr}$ concentration. KIM1 was significantly increased in the urine of cisplatin-treated 
rats at day 1 and day 3 . The results provided in vivo validation of the in vitro results. KIM-1 levels did not increase following treatment with D-galactosamine, a potent hepatotoxicant (43), demonstrating that it is specific to nephrotoxicity. We evaluated KIM-1 levels in a Cd-induced nephropathy model. Our data indicated that levels of KIM-1 in the urine are highly sensitive for the detection of kidney injury (44). In conclusion, KIM-1 is upregulated in renal disease and is associated with renal fibrosis and inflammation. Urinary KIM-1 is also associated with inflammation and renal function and reflects tissue KIM-1 levels, indicating that it can be used as a non-invasive biomarker for renal disease.

Cystatin C. Cystatin C is a low molecular weight protein (approximately $13.3 \mathrm{kDa}$ ) that is removed from the bloodstream by glomerular filtration. Cystatin $\mathrm{C}$ is a protease inhibitor that is normally expressed in nucleated cells and is solely excreted by the kidney without muscle catabolism $(45,46)$. Cystatin $C$ is not normally detected in the urine, but it has been found in the urine of patients with tubular damage. Urinary levels of cystatin $\mathrm{C}$ were significantly elevated in AKI after elective cardiac surgery (47). Compared with $\mathrm{SCr}$, it is less dependent on age, sex, race and muscle mass when measured in the serum after kidney damage (46). Previous studies have demonstrated that reduction in kidney function and GFR are positively correlated with blood levels of cystatin $\mathrm{C}(47,48)$. In patients with $\mathrm{AKI}$, serum cystatin $\mathrm{C}$ increased by more than $50 \%$ $14 \mathrm{hr}$ earlier than an observable increase in SCr (49). Thus, this study concluded that serum cystatin $\mathrm{C}$ levels are useful in the detection of AKI and may allow for the detection of AKI 1 to 2 days earlier than $\mathrm{Cr}$.

Osteopontin. Osteopontin is a glycoprotein that is highly expressed in bone and epithelial tissues (50) and is secreted in both phosphorylated and non-phosphorylated forms (51-53). It is expressed in various cell types, including macrophages, activated $\mathrm{T}$ cells, smooth muscle cells, and endothelial cells (54). Osteopontin is abundant in the bone matrix and is present in the kidney and epithelial cells as well as in other organs and body fluids (55). Osteopontin can be detected at high levels in human urine when the kidneys are markedly damaged by various nephrotoxicants, such as gentamicin, cisplatin, and cyclosporin (56). Kahles et al. (2014) reported that osteopontin was linked to obesity-induced adipose inflammation and insulin resistance (57). Therefore, pharmacological inhibition of osteopontin expression may provide a novel approach for the treatment of type 2 diabetes and its complications.

IL-18. IL-18 is a pro-inflammatory cytokine that is activated in proximal tubule cells and excreted in the urine following kidney injury (58). A previous study reported that IL-18 has been shown to exacerbate tubular necrosis, and neutralizing antibodies against IL-18 were found to reduce renal injury in mice (59). Furthermore, urinary excretion of IL-18 significantly increased $6 \mathrm{hr}$ after pediatric cardiac surgery, whereas SCr levels did not increase until 48 72 hr after surgery (60). Moreover, urinary IL-18 levels also markedly increased (up to $600 \mathrm{pg} / \mathrm{mL}$ ) $2 \mathrm{hr}$ after AKI in adults (61). Taken together, inhibition of IL-18 is protective against AKI in mice (62). In summary, the pro-inflammatory cytokine IL-18 is both a mediator and a biomarker of $\mathrm{AKI}$ in mice and humans.

N-acetyl-beta-D-glucosaminidase (NAG). N-acetylbeta-D-glucosaminidase (NAG) is a lysosomal enzyme present in proximal tubular cells. NAG is released into the urine following proximal tubule injury in the kidneys (63). It specifically cleaves $\mathrm{N}$-acetyl-glucosamine from larger precursors. NAG cannot be reabsorbed in the glomeruli because of its relatively high molecular weight; it is rapidly cleared from circulation by the liver (64). Urinary NAG concentration is a sensitive index of renal tubular function because its presence in the urine is primarily attributable to proximal tubule cell damage. Previous experiments have shown that NAG is a sensitive marker of acute ischemic and oxidative stress within the kidney. A significant elevation in the urinary concentration of NAG was observed in animals exposed to gentamicin, cisplatin, or lithium (65). However, the clinical utility of NAG remains limited as the urinary excretion of this enzyme is also increased in glomerular diseases such as diabetic nephropathy (66). A combination of urinary biomarkers such as KIM-1, NGAL (high specificity), and NAG (high sensitivity) may enhance the detection of early stage of AKI in patients following surgery.

Beta-2-Microglobulin ( $\left.\boldsymbol{\beta}_{2} \boldsymbol{M}\right)$. A number of low molecular weight proteins have been identified as markers of abnormal glomerular filtration, including $\alpha$-1-microglobulin $\left(\alpha_{1} \mathrm{M}\right), \beta$-2-microglobulin $\left(\beta_{2} \mathrm{M}\right)$, and retinol binding protein $(65) . \beta_{2} \mathrm{M}$ is a small $(11.8 \mathrm{kDa})$ subunit of the major histocompatibility class I complex, present in all nucleated cells (67). Circulating $\beta_{2} \mathrm{M}$ is cleared almost exclusively by the kidney, where it is freely filtered by the glomeruli and reabsorbed and metabolized in the proximal tubules (68). Therefore, the concentration of $\beta_{2} \mathrm{M}$ in the blood has been proposed to be a measure of GFR (69). A test for $\beta_{2} \mathrm{M}$ levels may be useful when known suspected kidney damage occurs, as it enables clinicians to distinguish between glomerular and tubular disorders of the kidney.

Glutathione-S-transferase (GST). GSTs are a family of cytosolic, microsomal, and membrane-bound enzymes. The GST alpha isoform is localized to the proximal tubular cells, whereas the GST pi isoform is confined to distal tubular cells (70). Increased levels of GST in the urine after nephrotoxic injury are attributed to leakage from the tubu- 
lar epithelial cells into the tubular lumen secondary to cell damage (71). In two rat strains, GST alpha indicated proximal tubular necrosis as early as $48 \mathrm{hr}$ after cisplatin-induced injury (72). In patients with rheumatoid arthritis, acute tubular injury from methotrexate and disease-modifying antirheumatic drugs could be ruled out by normal activity of GST alpha (73). GST alpha was the most sensitive biomarker for polymyxin-induced nephrotoxicity, outperforming the conventional biomarkers.

\section{POSSIBLE ROLE OF PKM2 IN AKI}

Pyruvate kinase (PK) catalyzes the final rate-limiting reaction in the glycolytic process, transfer of a high-energy phosphate group from phosphoenolpyruvate (PEP) to ADP, producing ATP and pyruvate $(74,75)$. In the PK subfamily, the M2 isoform (PKM2) is subjected to a complex regulation by both oncogenes and tumor suppressors, which allows for fine-tuning of PKM2 activity $(74,76)$. The less active form of PKM2 directs glucose to aerobic glycolysis, while active PKM2 directs glucose towards oxidative metabolism. In this paper, we will focus on our previous study on the regulation of PKM2 and its contribution to AKI.

The kidney cortex and plasma samples showed early decreases in glucose, a pyruvate metabolite, and lactate during glucose metabolism (77). Intermediate molecules in the TCA cycle, including succinate and malate, showed a similar pattern in the plasma but not in the kidney cortex (78). These patterns of metabolic change during energy metabolism in the kidney cortex and the plasma can be observed after inflammatory disease, ischemia, or toxicant exposure. Metabolomic studies have contributed to the discovery of new biochemical parameters and the understand- ing of their role in disease. The metabolites that are altered during the process of AKI include amino acids, intermediates of the glucose pathway, and lipids metabolism. To obtain new insight into the relationship between PKM2 expression and differentially present metabolites in normal human kidney tubular HK-2 cells following cisplatin-induced in vitro $\mathrm{AKI}$, we used $\left[{ }^{1} \mathrm{H}\right] \mathrm{NMR}$ in the samples of $\mathrm{HK}-2$ cells or conditioned media.

First, HK-2 cells were plated in 96-well plates at $1 \times 10^{4}$ cells/well and were incubated at $37^{\circ} \mathrm{C}$ with $5 \% \mathrm{CO}_{2}$ for $24 \mathrm{hr}$. The culture plates were then incubated with fresh medium containing cisplatin $(10 \mu \mathrm{M})$ for $6,12,24$, or $48 \mathrm{hr}$. Cell and conditioned media samples were stored in $-80^{\circ} \mathrm{C}$ freezer until NMR analysis. The metabolites from HK-2 cells or conditioned media treated with cisplatin were measured using $\left[{ }^{1} \mathrm{H}\right] \mathrm{NMR}$ to establish cellular metabolite profiles. In the conditioned media of cisplatin-treated HK-2 cells, lactate, acetate, and glutamate levels were significantly increased in a time-dependent manner. Notably, lactate concentration increased 12 -fold $48 \mathrm{hr}$ after incubation with cisplatin (Fig. 2). In HK-2 cells, acetate and glutamate levels were also increased in a time-dependent manner, but acetate levels decreased (Fig. 3). Moreover, glutamate concentration increased to protect against tissue injury, and alanine accumulated to inhibit the proteolysis of skeletal muscle proteins, resulting in increased serum levels of glutamate and alanine (data not shown). Based on our study, we suggest that cisplatin-treated HK-2 cells underwent a metabolic switch from pyruvate to lactate for energy production. The data presented are consistent with a model in which a cisplatin-induced alteration in glucose utilization influences SIRT1 and AMPK activity (79). Lactate is mainly generated by anaerobic glycolysis and is not associated with the primary energy supply under normal conditions. During
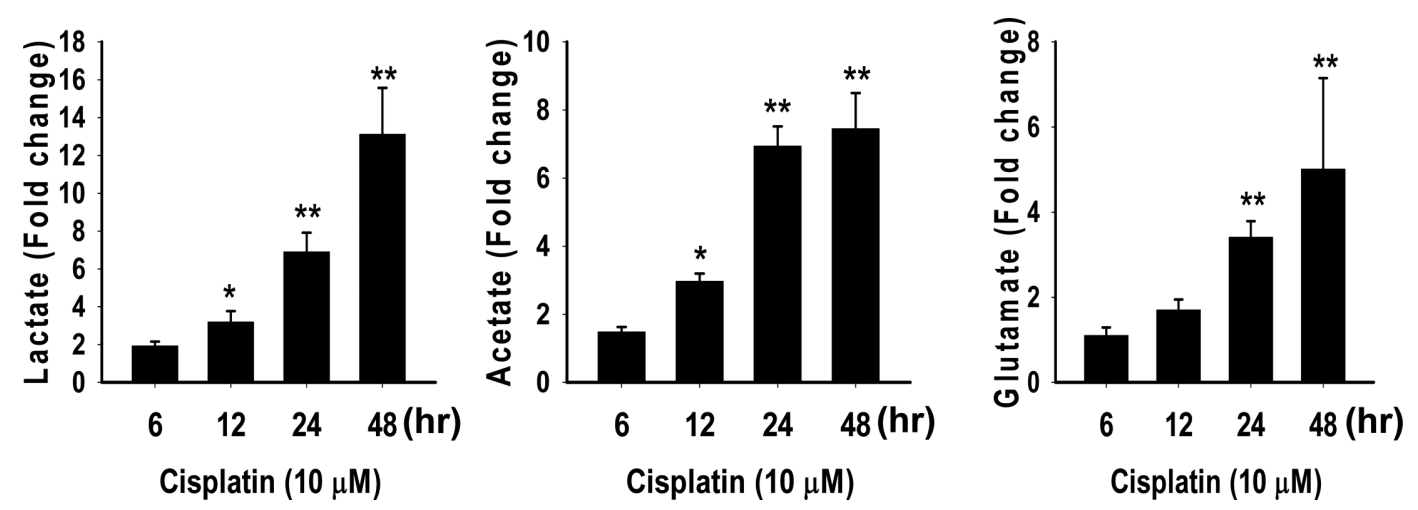

Fig. 2. Fold change in metabolites observed in conditioned media from HK-2 cells treated with cisplatin ( $10 \mu \mathrm{M})$. Fold changes were calculated as the ratio of cisplatin-treated groups and control groups (cisplatin-treated/control) of a given metabolite at each time point. Data are representative of 3 independent experiments. Concentrations of metabolites were detected by [ $\left.{ }^{1} \mathrm{H}\right] \mathrm{NMR}$ in conditioned media of HK-2 cells after cisplatin-treatment. Data were then calibrated to TSP- $\mathrm{d}_{4}$ at $\delta 0.00 \mathrm{ppm}$. Spectral assignment was performed by Chenomx NMR Suite 7.1 software (Chenomx Inc., Edmonton, Canada) and compared with published data. After processing, data were reduced into 920 spectral integral regions corresponding to a chemical shift range of $\delta 0.2 \mathrm{ppm}-10 \mathrm{ppm}$ using the Chenomx NMR Suite. 

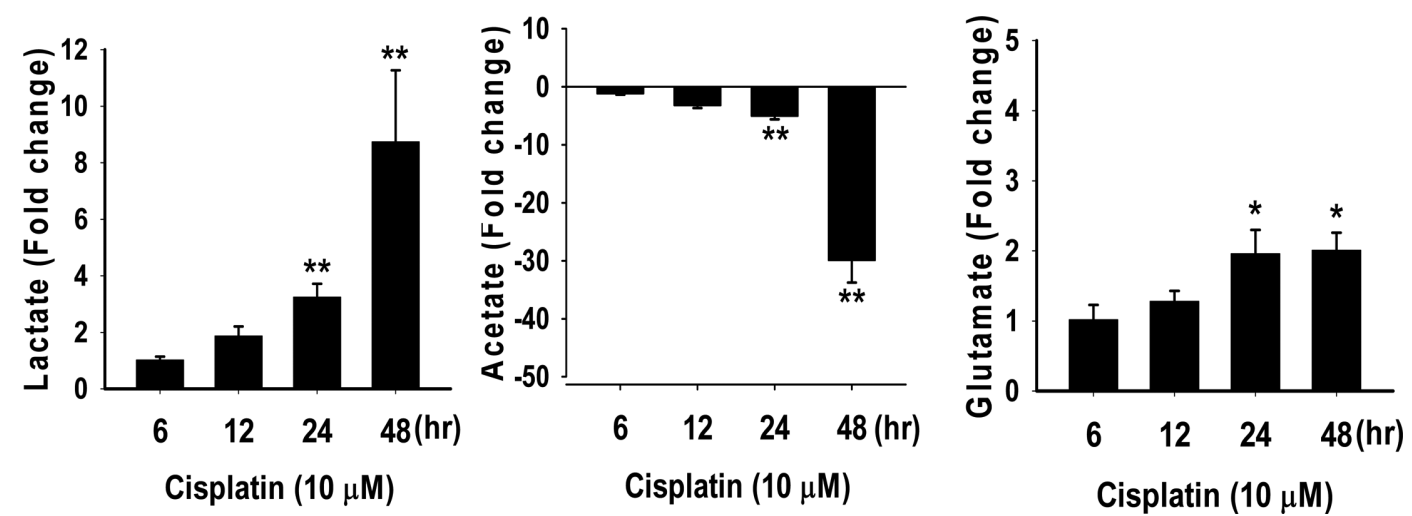

Fig. 3. Fold change of metabolites observed in the lysates of HK-2 cells treated with cisplatin $(10 \mu \mathrm{M})$. Fold changes were calculated as the ratio of cisplatin-treated groups and control groups (cisplatin-treated/control) of a given metabolite at each time point. Data are representative of 3 independent experiments. Concentrations of metabolites were detected by $\left[{ }^{1} \mathrm{H}\right] \mathrm{NMR}$ in lysates of HK-2 cells after cisplatin-treatment. Data were then normalized to TSP- $\mathrm{d}_{4}$ at $\delta 0.00 \mathrm{ppm}$. Spectral assignment was performed by Chenomx NMR Suite 7.1 software (Chenomx Inc., Edmonton, Canada) and compared with published data. After processing, data were reduced into 920 spectral integral regions corresponding to a chemical shift range of $\delta 0.2 \mathrm{ppm}-10 \mathrm{ppm}$ using the Chenomx NMR Suite.

hypoxia, an insufficient oxygen supply can reduce Krebs cycle reactions, thus leading to a reduction in the production of ATP, and an enhancement of glycolysis, resulting in a decreased ability of the liver and kidneys to remove wastes and, ultimately, to accumulation of lactate in plasma $(80,81)$.

Lactate is a universal marker of the inflammatory process, and increases in lactate levels have been observed in the plasma of patients with rheumatoid arthritis (82). Pyruvate may be converted to lactate by PKM2, and increased urine lactate level is a strong predictor of AKI. Lactate is a waste product of normal metabolism that is reversibly converted from pyruvate via the enzyme lactate dehydrogenase (LDHA). In our previous study, metabolomics analysis showed altered urinary glucose, amino acid, and TCA intermediates that preceded $\mathrm{SCr}$ in cisplatin-induced acute renal failure (31). Therefore, we suggest that a metabolomic study may be useful for detecting biochemical changes in amino acid, nucleic acid, and carbohydrate metabolites in the serum or urine of patients with AKI, as well as unidentified metabolites with novel functions. Understanding these changes in metabolic products may be important for developing new strategies to prevent AKI or stop its progression in patients with CKD.

To elucidate the molecular role of PKM2 during glycolysis in kidney proximal tubular cells, we investigated the secretion of PKM2 in the conditioned media of HK-2 cells treated with cisplatin $(10 \mu \mathrm{M})$. Previously, we reported that cisplatin-induced cell damage was linked closely to apoptosis in renal tubular HK-2 cells (42). In addition, we observed a relationship between PKM2 expression and apoptosisrelated molecules. These results indicate that PKM2 may be secreted or leak from cells after severe apoptotic cell damage. When apoptosis was blocked, cisplatin-mediated PKM2 secretion in conditioned media was markedly inhibited. Therefore, our data suggest that cisplatin-induced apoptosis may be responsible for the increased release of PKM2 in the conditioned media. In contrast, cisplatin treatment increased the levels of PKM2 in conditioned media of kidney cells but not in liver cells or breast cells (42). The increase of PKM2 levels in conditioned media was also observed following treatment with other nephrotoxic agents such as $\mathrm{CdCl}_{2}, \mathrm{HgCl}_{2}$, and cyclosporine A. Therefore, PKM2 as a biomarker of cisplatin-induced AKI has been evaluated in vivo. PKM2 was detected in the urine of rats injected with cisplatin $(10 \mathrm{mg} / \mathrm{kg})$ at 1 day and 3 days after treatment (Fig. 4). Furthermore, a large number of metabolites were decreased from day 1 to 3 relative to the control, including citrate, $c i s$-aconitate, trigonelline, hippurate, and 3-indoxylsulfate, in the urine of cisplatin-treated rats (31). Similar to the in vitro study, lactate, a metabolic product of pyruvate, was significantly increased on day 1 and day 3 . This study provided evidence that PKM2 can potentially be used as a sensitive biomarker for nephrotoxicity. Our data suggest that the response to cisplatin-induced AKI encompassed several aspects of energy metabolism in kidney tissue. After the early steps of the AKI process, the PKM2 isoenzyme is expressed in the kidney, followed by the loss of PKM2. However, confirming this relationship is difficult and needs further investigation.

\section{CONCLUSIONS}

Kidneys play an important role in the excretion of xenobiotics, including drugs and toxic environmental agents. Due to their secretory functions, proximal tubular cells are easily exposed to higher concentrations of chemical metabolites than are those occurring in plasma or extracellular 


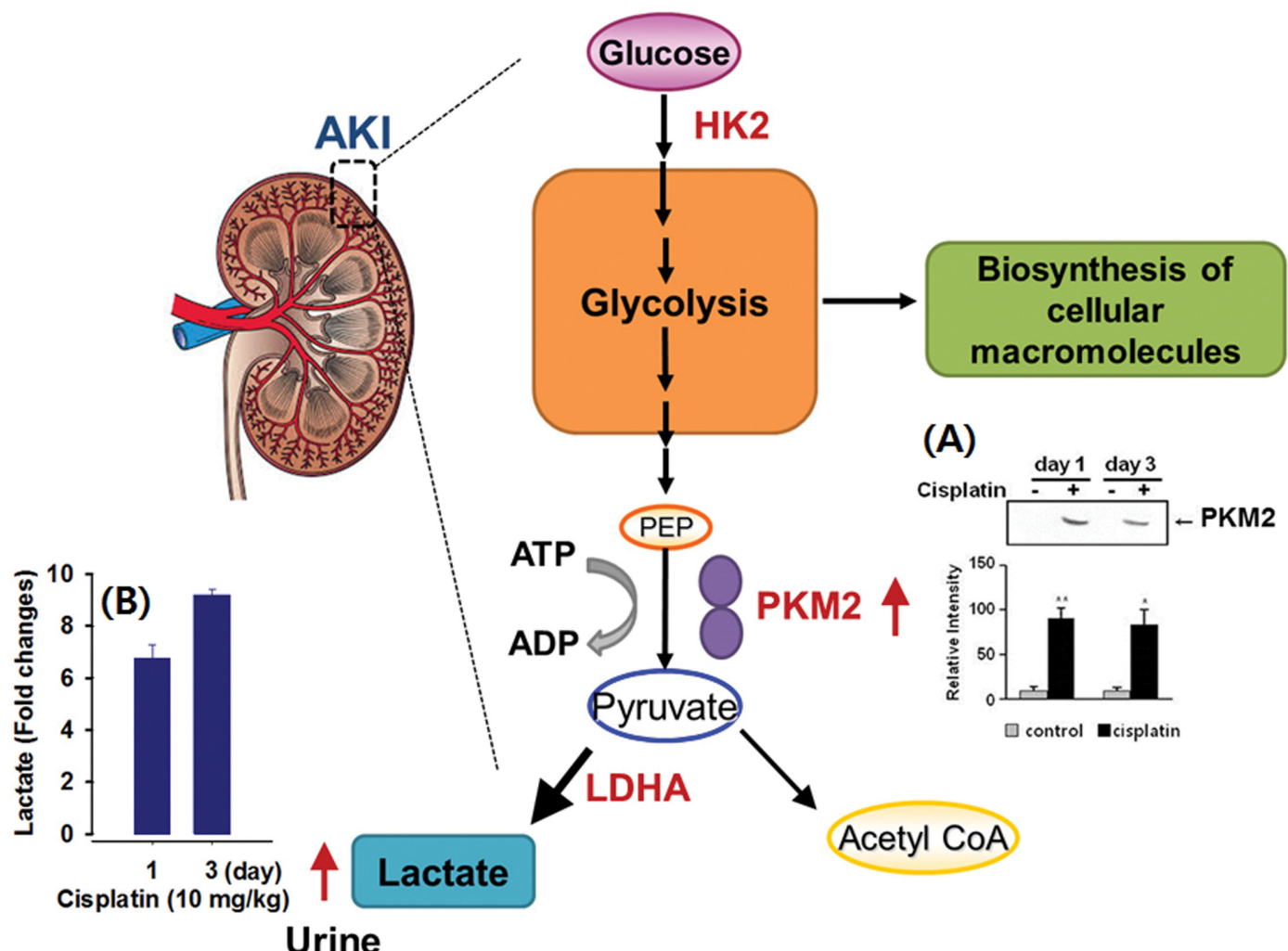

Fig. 4. Schematic illustrating glucose metabolism during acute kidney damage. Pyruvate kinase M2 (PKM2) catalyzes the rate-limiting step of glycolysis, controlling the conversion of phosphoenolpyruvate (PEP) to pyruvate, and thus ATP generation. PKM2, a cytosolic protein, is highly expressed in the tubular cells because of pro-apoptotic stimuli in the early stage of AKI. Finally, PKM2 may be released into the urine by leakage through the damaged cell membranes in cell death-inducing conditions. (A) Increased levels of PKM2 were detected in cisplatin-treated rats. Urine samples of rats treated with cisplatin were subjected to immunoblot analysis for PKM2. Data are representative of 3 independent experiments. (B) The fold changes of lactate detected by [ $\left.{ }^{1} H\right] N M R$ in the urine of Sprague-Dawley rats are indicated. Male Sprague-Dawley rats were administered saline (control) or cisplatin (10 mg/kg), and urine samples were collected at the indicated time points. The analysis of lactate in urine samples was carried out with a Varian analyzer (Varian Inc., Palo Alto, CA) with a working frequency of $600.167 \mathrm{MHz}$ at a temperature of $299.1 \mathrm{~K}$.

fluids. Therefore, urine can include various proteins and metabolites that are highly sensitive and specific and thus allow for the detection of AKI. The best ways to reduce the chance of kidney damage and to protect kidney function are to prevent AKI or to treat AKI as early as possible. However, traditional biomarkers such as $\mathrm{SCr}$ and BUN lack the sensitivity and/or specificity needed to detect AKI before significant loss of renal function. Urinary enzymes or proteins have been proposed as promising non-invasive markers for the early detection of AKI. In this review, we focused on the major biomarkers that have sensitive and specific characteristics for the diagnosis of AKI. We also evaluated PKM2 as an early biomarker of AKI. This review will help understand the biological basis of specific biomarkers that will contribute to improving the early detection or diagnosis of AKI. However, the use of current biomarkers or newer biomarkers discovered in the future can be combined with the use of SCr and BUN to increase prognostic ability; these combined biomarkers will enhance the possibility for early detection of AKI.

\section{ACKNOWLEDGEMENTS}

This work was supported by the Korea Foundation for the Advancement of Science \& Creativity (KOFAC), and funded by the Korean Government (MOE).

\section{CONFLICT OF INTEREST}

Authors declare that they are no conflicts of interest.

\section{REFERENCES}

1. Van Biesen, W., Vanholder, R. and Lamiere, N. (2006) Defining acute renal failure: RIFLE and beyond. Clin. J. Am. Soc. Nephrol., 1, 1314-1319.

2. Basile, D.P., Anderson, M.D. and Sutton, T.A. (2012) Pathophysiology of acute kidney injury. Compr. Physiol., 2, 1303- 
1353.

3. Ricci, Z., Cruz, D.N. and Ronco, C. (2011) Classification and staging of acute kidney injury: beyond the RIFLE and AKIN criteria. Nat. Rev. Nephrol., 7, 201-208.

4. Thadhani, R., Pascual, M. and Bonventre, J.V. (1996) Acute renal failure. N. Engl. J. Med., 334, 1448-1460.

5. Ympa, Y.P., Sakr, Y., Reinhart, K. and Vincent, J.L. (2005) Has mortality from acute renal failure decreased? A systematic review of the literature. Am. J. Med., 118, 827-832.

6. Espandiari, P., Zhang, J., Rosenzweig, B.A., Vaidya, V.S., Sun, J., Schnackenberg, L., Herman, E.H., Knapton, A., Bonventre, J.V., Beger, R.D., Thompson, K.L. and Hanig, J. (2008) The utility of a rodent model in detecting pediatric drug-induced nephrotoxicity. Toxicol. Sci., 99, 637-648.

7. Zhou, Y., Vaidya, V.S., Brown, R.P., Zhang, J., Rosenzweig, B.A., Thompson, K.L., Miller, T.J., Bonventre, J.V. and Goering, P.L. (2008) Comparison of kidney injury molecule-1 and other nephrotoxicity biomarkers in urine and kidney following acute exposure to gentamicin, mercury, and chromium. Toxicol. Sci., 101, 159-170.

8. Moran, S.M. and Myers, B.D. (1985) Course of acute renal failure studied by a model of creatinine kinetics. Kidney Int., 27, 928-937.

9. Star, R.A. (1998) Treatment of acute renal failure, Kidney Int., 54, 1817-1831.

10. Mehta, R.L., Kellum, J.A., Shah, S.V., Molitoris, B.A., Ronco, C., Warnock, D.G. and Levin, A. (2007). Acute Kidney Injury Network: report of an initiative to improve outcomes in acute kidney injury. Crit. Care, 11, R3.

11. Holley, J.L. (2009) Clinical approach to the diagnosis of acute renal failure (5th edition). Primer on Kidney Diseases, Philadelphia. pp. 118-169.

12. Smith, M.C. (2004) Acute renal failure. (3rd edition). Clinical Decisions in Urology, Hamilton, Ontario, Canada.

13. Food and Drug Administration (FDA). (2009) Predictive safety testing consortium (PSTC). Available from: http:// www.fda.gov/oc/initiatives/criticalpath/projectsummary/consortium.html. pp. 396-435.

14. Vaidya, V.S., Ferguson, M.A. and Bonventre, J.V. (2008) Biomarkers of acute kidney injury. Annu. Rev. Pharmacol. Toxicol., 48, 463-493.

15. Astor, B.C., Muth, B., Kaufman, D.B., Pirsch, J.D., Michael Hofmann, R. and Djamali, A. (2013) Serum $\beta 2$-microglobulin at discharge predicts mortality and graft loss following kidney transplantation. Kidney Int., 84, 810-817.

16. Bernier, G.M. (1980) $\beta 2$-Microglobulin: structure, function and significance. Vox Sang., 38, 323-327.

17. Vaidya, V.S., Ferguson, M.A. and Bonventre, J.V. (2008) Biomarkers of acute kidney injury. Annu. Rev. Pharmacol. Toxicol., 48, 463-493.

18. Caccamo, A.E., Scltriti, M., Caporali, A., D’Arca, D., Scorcioni, F., Astancolle, S., Mangiola, M. and Bettuzzi, S. (2004) Cell detachment and apoptosis induction of immortalizaed human prostate epithelial cells are associated with early accumulation of a $45 \mathrm{kDa}$ nuclear isoform of clusterin. Biochem. J., 382, 157-168.

19. Rampoldi, L., Scolari, F., Amoroso, A., Ghiggeri, G. and Devuyst, O. (2011) The rediscovery of uromodulin (TammHorsfall protein): from tubulointerstitial nephropathy to chronic kidney disease. Kidney Int., 80, 338-347.

20. Yan, Q., Sui, W., Wang, B., Zou, H., Zou, G. and Luo, H. (2012) Expression of MMP-2 and TIMP-1 in renal tissue of patients with chronic active antibody-mediated renal graft rejection. Diagn. Pathol., 7, 141.

21. Dinarello, C.A., Novick, D., Rubinstein, M. and Lonnemann, G. (2003) Interleukin 18 and interleukin 18 binding protein: possible role in immunosuppression of chronic renal failure. Blood Purif., 21, 258-270.

22. Campbell, J.A., Corrigall, A.V., Guy, A. and Kirsch, R.E. (1991) Immunohistologic localization of alpha, mu, and pi class glutathione S-transferases in human tissues. Cancer, 67, 1608-1613.

23. Xie, Y., Sakatsume, M., Nishi, S., Narita, I., Arakawa, M. and Gejyo, F. (2001) Expression, roles, receptors, and regulation of osteopontin in the kidney. Kidney Int., 60, 1645-1657.

24. Yu, Y., Jin, H., Holder, D., Ozer, J.S., Villarreal, S., Shughrue, P., Shi, S., Figueroa, D.J., Clouse, H., Su, M., Muniappa, N., Troth, S.P., Bailey, W., Seng, J., Aslamkhan, A.G., Thudium, D., Sistare, F.D. and Gerhold, D.L. (2010) Urinary biomarkers trefoil factor 3 and albumin enable early detection of kidney tubular injury. Nat. Biotechnol., 28, 470-477.

25. Yang, J., Goetz, D., Li, J.Y., Wang, W., Mori, K., Setlik, D., Du, T., Erdjument-Bromage, H., Tempst, P., Strong, R. and Barasch, J. (2002) An iron delivery pathway mediated by a lipocalin. Mol. Cell, 10, 1045-1056.

26. Borregaard, N., Sehested, M., Nielsen, B.S., Sengelov, H. and Kjeldsen, L. (1995) Biosynthesis of granule proteins in normal human bone marrow cells. Gelatinase is a marker of terminal neutrophil differentiation. Blood, 85, 812-817.

27. Mishra, J., Dent, C., Tarabishi, R., Mitsnefes, M.M., Ma, Q., Kelly, C., Ruff, S.M., Zahedi, K., Shao, M., Bean, J., Mori, K., Barasch, J. and Devarajan, P. (2005) Neutrophil gelatinase-associated lipocalin (NGAL) as a biomarker for acute renal injury after cardiac surgery. Lancet, 365, 1231-1238.

28. Moran, S.M. and Myers, B.D. (1985) Course of acute renal failure studied by a model of creatinine kinetics. Kidney Int., 27, 928-937.

29. Bennett, M.R., Nehus, E., Haffner, C., Ma, Q. and Devarajan, P. (2015) Pediatric reference ranges for acute kidney injury biomarkers. Pediatr. Nephrol., 30, 677-685.

30. Bennett, M., Dent, C.L., Ma, Q., Dastrala, S., Grenier, F., Workman, R., Syed, H., Ali, S., Barasch, J. and Devarajan, P. (2008) Urine NGAL predicts severity of acute kidney injury after cardiac surgery: a prospective study. Clin. J. Am. Soc. Nephrol., 3, 665-673.

31. Won, A.J., Kim, S., Kim, Y.G., Kim, K.B., Choi, W.S., Kacew, S., Kim, K.S., Jung, J.H., Lee, B.M., Kim, S. and Kim, H.S. (2015) Discovery of urinary metabolomic biomarkers for early detection of acute kidney injury. Mol. Biosyst., 12, 133144.

32. Xin, C., Yulong, X., Yu, C., Changchun, C., Feng, Z. and Xinwei, M. (2008) Urine neutrophil gelatinase-associated lipocalin and interleukin-18 predict acute kidney injury after cardiac surgery. Renal Failure, 30, 904-913.

33. Silberstein, J.L., Sprenkle, P.C., Su, D., Power, N.E., Tarin, T.V., Ezell, P., Sjoberg, D.D., Feifer, A., Fleisher, M., Russo, P. and Touijer, K.A. (2013) Neutrophil gelatinase-associated lipocalin (NGAL) levels in response to unilateral renal isch- 
aemia in a novel pilot two-kidney porcine model. BJU Int., 112, 517-525.

34. Sprenkle, P.C., Wren, J., Maschino, A.C., Feifer, A., Power, N., Ghoneim, T., Sternberg, I., Fleisher, M. and Russo, P. (2013) Urine neutrophil gelatinase-associated lipocalin as a marker of acute kidney injury after kidney surgery. J. Urol., 190, 159-164.

35. Zekey, F., Senkul, T., Ates, F., Soydan, H., Yilmaz, O. and Baykal, K. (2012) Evaluation of the impact of shock wave lithotripsy on kidneys using a new marker: how do neutrophil gelatinese-associated lypocalin values change after shock wave lithotripsy?. Urology, 80, 267-272.

36. Ichimura, T., Bonventre, J.V., Bailly, V., Wei, H., Hession, C.A., Cate, R.L. and Sanicola, M. (1998) Kidney Injury Molecule-1 (KIM-1), a putative epithelial cell adhesion molecule containing a novel immunoglobulin domain, is up-regulated in renal cells after injury. J. Biol. Chem., 273, 4135-4142.

37. Han, W.K., Bailly, V., Abichandani, R., Thadhani, R. and Bonventre, J.V. (2002) Kidney Injury Molecule-1 (KIM-1): a novel biomarker for human renal proximal tubule injury. Kidney Int., 62, 237-244.

38. van Timmeren, M.M., van den Heuvel, M.C., Bailly, V., Bakker, S.J., van Goor, H. and Stegeman, C.A. (2007) Tubular kidney injury molecule-1 (KIM-1) in human renal disease. $J$. Pathol., 212, 209-217.

39. Solez, K., Colvin, R.B., Racusen, L.C., Haas, M., Sis, B., Mengel, M., Halloran, P.F., Baldwin, W., Banfi, G., Collins, A.B., Cosio, F., David, D.S., Drachenberg, C., Einecke, G., Fogo, A.B., Gibson, I.W., Glotz, D., Iskandar, S.S., Kraus, E., Lerut, E., Mannon, R.B., Mihatsch, M., Nankivell, B.J., Nickeleit, V., Papadimitriou, J.C., Randhawa, P., Regele, H., Renaudin, K., Roberts, I., Seron, D., Smith, R.N. and Valente, M. (2008) Banff 07 classification of renal allograft pathology: updates and future directions. Am. J. Transplant., 8, 753-760.

40. Han, W.K., Waikar, S.S., Johnson, A., Betensky, R.A., Dent, C.L., Devarajan, P. and Bonventre, J.V. (2008) Urinary biomarkers in the early diagnosis of acute kidney injury. Kidney Int., 73, 863-869.

41. Bonventre, J.V. (2009) Bonventre Kidney injury molecule-1 (KIM-1): a urinary biomarker and much more. Nephrol. Dial. Transplant., 24, 3265-3268.

42. Kim, S.Y., Sohn, S.J., Won, A.J., Kim, H.S. and Moon, A. (2014) Identification of noninvasive biomarkers for nephrotoxicity using HK-2 human kidney epithelial cells. Toxicol. Sci., 140, 247-258.

43. Itokazu, Y., Segawa, Y., Inoue, N. and Omata, T. (1999) Dgalactosamine induced mouse hepatic apoptosis: possible involvement with tumor necrosis factor, but not with caspase3 activity. Biol. Pharm. Bull., 22, 1127-1130.

44. Lee, Y.K., Park, E.Y., Kim, S., Son, J.Y., Kim, T.H., Kang, W.G., Jeong, T.C., Kim, K.B., Kwack, S.J., Lee, J., Kim, S., Lee, B.M. and Kim, H.S. (2014) Evaluation of cadmiuminduced nephrotoxicity using urinary metabolomic profiles in sprague-dawley male rats. J. Toxicol. Environ. Health Part A, 77, 1384-1398.

45. de Boer, I.H., Katz, R., Cao, J.J., Fried, L.F., Kestenbaum, B., Mukamal, K., Rifkin, D.E., Sarnak, M.J., Shlipak, M.G. and Siscovick, D.S. (2009) Cystatin C, albuminuria, and mortality among older adults with diabetes. Diabetes Care, 32, 1833-
1838.

46. Beringer, P.M., Hidayat, L., Heed, A., Zheng, L., Owens, H., Benitez, D. and Rao, A.P. (2009) GFR estimates using cystatin $\mathrm{C}$ are superior to serum creatinine in adult patients with cystic fibrosis. J. Cystic Fibrosis, 8, 19-25.

47. Koyner, J.L., Bennett, M.R., Worcester, E.M., Ma, Q., Raman, J., Jeevanandam, V., Kasza, K.E., O’Connor, M.F., Konczal, D.J., Trevino, S., Devarajan, P. and Murray, P.T. (2008) Urinary cystatin $\mathrm{C}$ as an early biomarker of acute kidney injury following adult cardiothoracic surgery. Kidney Int., 74, 10591069.

48. Villa, P., Jimenez, M., Soriano, M.C., Manzanares, J. and Casasnovas, P. (2005) Serum cystatin C concentration as a marker of acute renal dysfunction in critically ill patients. Crit. Care, 9, R139-143.

49. Herget-Rosenthal, S., Marggraf, G., Hüsing, J., Göring, F., Pietruck, F., Janssen, O., Philipp, T. and Kribben, A. (2004) Early detection of acute renal failure by serum cystatin C. Kidney Int., 66, 1115-1122.

50. Oldberg, A., Franzén, A. and Heinegård, D. (1986) Cloning and sequence analysis of rat bone sialoprotein (osteopontin) cDNA reveals an Arg-Gly-Asp cell-binding sequence. Proc. Natl. Acad. Sci. U.S.A., 83, 8819-8823.

51. Patarca, R., Freeman, G.J., Singh, R.P., Wei, F.Y., Durfee, T., Blattner, F., Regnier, D.C., Kozak, C.A., Mock, B.A., Morse, H.C. $3^{\text {rd }}$., Jerrells, T.R. and Cantor, H. (1989) Structural and functional studies of the early T lymphocyte activation 1 (Eta1) gene. Definition of a novel T cell-dependent response associated with genetic resistance to bacterial infection. J. Exp. Med., 170, 145-161.

52. Nomura, S., Wills, A.J., Edwards, D.R., Heath, J.K. and Hogan, B.L. (1988) Developmental expression of 2ar (osteopontin) and SPARC (osteonectin) RNA as revealed by in situ hybridization. J. Cell Biol., 106, 441-450.

53. Shiraga, H., Min, W., VanDusen, W.J., Clayman, M.D., Miner, D., Terrell, C.H., Sherbotie, J.R., Foreman, J.W., Przysiecki, C., Neilson, E.G. and Hoyer, J.R. (1992) Inhibition of calcium oxalate crystal growth in vitro by uropontin: another member of the aspartic acid-rich protein superfamily. Proc. Natl. Acad. Sci. U.S.A., 89, 426-430.

54. Brown, L.F., Berse, B., Van de Water, L., Papadopoulos-Sergiou, A., Perruzzi, C.A., Manseau, E.J., Dvorak, H.F. and Senger, D.R. (1992) Expression and distribution of osteopontin in human tissues: widespread association with luminal epithelial surfaces. Mol. Biol. Cell, 3, 1169-1180.

55. Chen, J., Singh, K., Mukherjee, B.B. and Sodek, J. (1993) Developmental expression of osteopontin (OPN) mRNA in rat tissues: evidence for a role for OPN in bone formation and resorption. Matrix, 13, 113-123.

56. Alchi, B., Nishi, S., Kondo, D., Kaneko, Y., Matsuki, A., Imai, N., Ueno, M., Iguchi, S., Sakatsume, M., Narita, I., Yamamoto, T. and Gejyo, F. (2005) Osteopontin expression in acute renal allograft rejection. Kidney Int., 67, 886-896.

57. Kahles, F., Findeisen, H.M. and Bruemmer, D. (2014) Osteopontin: A novel regulator at the cross roads of inflammation, obesity and diabetes. Mol. Metab., 3, 384-393.

58. Okamura, H., Tsutsi, H., Komatsu, T., Yutsudo, M., Hakura, A., Tanimoto, T., Torigoe, K., Okura, T., Nukada, Y., Hattori, K., Akita, K., Namba, M., Tanabe, F., Konishi, K., Fukuda, S. 
and Kurimoto, M. (1995) Cloning of a new cytokine that induces IFN-gamma production by T cells. Nature, 378, 8891.

59. Boros, P. and Bromberg, J.S. (2006) New cellular and molecular immune pathways in ischemia/reperfusion injury. Am. J. Transplant., 6, 652-658.

60. Parikh, C.R., Mishra, J., Thiessen-Philbrook, H., Dursun, B., Ma, Q., Kelly, C., Dent, C., Devarajan, P. and Edelstein, C.L. (2006) Urinary IL-18 is an early predictive biomarker of acute kidney injury after cardiac surgery. Kidney Int., 70, 199-203.

61. Xin, C., Yulong, X., Yu, C., Changchun, C., Feng, Z. and Xinwei, M. (2008) Urine neutrophil gelatinase-associated lipocalin and interleukin-18 predict acute kidney injury after cardiac surgery. Renal Failure, 30, 904-913.

62. He, Z., Lu, L., Altmann, C., Hoke, T.S., Ljubanovic, D., Jani, A., Dinarello, C.A., Faubel, S. and Edelstein, C.L. (2008) Interleukin-18 binding protein transgenic mice are protected against ischemic acute kidney injury. Am. J. Physiol. Renal Physiol., 295, F1414-1421.

63. Drake, P.L., Krieg, E., Teass, A.W. and Vallyathan, V. (2002) Two assays for urinary N-acetyl-beta-D-glucosaminidase compared. Clin. Chem., 48, 1604-1605.

64. Ali, R.J., Al-Obaidi, F.H. and Arif, H.S. (2014) The role of urinary $\mathrm{N}$-acetyl beta-D-glucosaminidase in children with urological problems. Oman Med. J., 29, 285-288.

65. Vaidya, V.S., Ozer, J.S., Dieterle, F., Collings, F.B., Ramirez, V., Troth, S., Muniappa, N., Thudium, D., Gerhold, D., Holder, D.J., Bobadilla, N.A., Marrer, E., Perentes, E., Cordier, A., Vonderscher, J., Maurer, G., Goering, P.L., Sistare, F.D. and Bonventre, J.V. (2010) Kidney injury molecule-1 outperforms traditional biomarkers of kidney injury in preclinical biomarker qualification studies. Nat. Biotechnol., 28, 478-485.

66. Marchewka, Z., Kuźniar, J. and Długosz, A. (2001) Enzymuria and beta2-mikroglobulinuria in the assessment of the influence of proteinuria on the progression of glomerulopathies. Int. Urol. Nephrol., 33, 673-676.

67. Tolkoff-Rubin, N.E., Rubin, R.H. and Bonventre, J.V. (1988) Noninvasive renal diagnostic studies. Clin. Lab. Med., 8, 507526 .

68. Schaub, S., Wilkins, J.A., Antonovici, M., Krokhin, O., Weiler, T., Rush, D. and Nickerson, P. (2005) Proteomic-based identification of cleaved urinary beta2-microglobulin as a potential marker for acute tubular injury in renal allografts. Am. J. Transplant., 5, 729-738.

69. Donadio, C., Lucchesi, A., Ardini, M. and Giordani, R. (2001) Cystatin $\mathrm{C}$, beta 2-microglobulin, and retinol-binding protein as indicators of glomerular filtration rate: comparison with plasma creatinine. J. Pharm. Biomed. Anal., 24, 835-842.
70. Branten, A.J., Mulder, T.P., Peters, W.H., Assmann, K.J. and Wetzels, J.F. (2000) Urinary excretion of glutathione S transferases alpha and pi in patients with proteinuria: reflection of the site of tubular injury. Nephron, 85, 120-126.

71. Harrison, D.J., Kharbanda, R., Cunningham, D.S., McLellan, L.I., and Hayes, J.D. (1989) Distribution of glutathione Stransferase isoenzymes in human kidney: basis for possible markers of renal injury. J. Clin. Pathol., 42, 624-628.

72. Gautier, J.C., Riefke, B., Walter, J., Kurth, P., Mylecraine, L., Guilpin, V., Barlow, N., Gury, T., Hoffman, D., Ennulat, D., Schuster, K., Harpur, E. and Pettit, S. (2010) Evaluation of novel biomarkers of nephrotoxicity in two strains of rat treated with Cisplatin. Toxicol. Pathol., 38, 943-956.

73. Svendsen, K.B., Ellingsen, T., Bech, J.N., Pfeiffer-Jensen, M., Stengaard-Pedersen, K. and Pedersen, E.B. (2005) Urinary excretion of $\alpha$-GST and albumin in rheumatoid arthritis patients treated with methotrexate or other DMARDs alone or in combination with NSAIDs. Scand. J. Rheumatol., 34, 3439.

74. Christofk, H.R., Vander Heiden, M.G., Harris, M.H., Ramanathan, A., Gerszten, R.E., Wei, R., Fleming, M.D., Schreiber, S.L. and Cantley, L.C. (2008) The M2 splice isoform of pyruvate kinase is important for cancer metabolism and tumour growth. Nature, 452, 230-233.

75. Mazurek, S., Drexler, H.C., Troppmair, J., Eigenbrodt, E. and Rapp, U.R. (2007) Regulation of pyruvate kinase type M2 by A-Raf: a possible glycolytic stop or go mechanism. Anticancer Res., 27, 3963-3971.

76. Muirhead, H. (1990) Isoenzymes of pyruvate kinase. Biochem. Soc. Trans., 18, 193-196.

77. Weiss, R.H. and Kim, K. (2011) Metabolomics in the study of kidney diseases. Nat. Rev. Nephrol., 8, 22-33.

78. Zager, R.A., Johnson, A.C. and Becker, K. (2014) Renal cortical pyruvate depletion during AKI. J. Am. Soc. Nephrol., 25, 998-1012.

79. Wakino, S., Hasegawa, K. and Itoh, H. (2015) Sirtuin and metabolic kidney disease. Kidney Int., 88, 691-698.

80. He, G., Jiang, Y., Zhang, B. and Wu, G. (2014) The effect of HIF-1 $\alpha$ on glucose metabolism, growth and apoptosis of pancreatic cancerous cells. Asia Pac. J. Clin. Nutr., 23, 174-180.

81. Bartrons, R. and Caro, J. (2007) Hypoxia, glucose metabolism and the Warburg's effect. J. Bioenerg. Biomembr., 39, 223-229.

82. Yang, X.Y., Zheng, K.D., Lin, K., Zheng, G., Zou, H., Wang, J.M., Lin, Y.Y., Chuka, C.M., Ge, R.S., Zhai, W. and Wang, J.G. (2015) Energy metabolism disorder as a contributing factor of rheumatoid arthritis: a comparative proteomic and metabolomic study. PLoS One, 10, e0132695. 